\title{
¿APLICACIÓN TOTAL O COMBINADA DE NORM AS PENALES? A PROPÓSITO DE UN (DES)ACUERDO PLENARIO
}

\author{
Aldo Martín Figueroa Navarro**
}

\section{Resumen}

La Corte Suprema, mediante Acuerdo Plenario en mayoría, ha consagrado el principio de combinación de leyes penales. Formalmente, la decisión adoptada no tiene eficacia normativa pues no refleja una posición unánime, lo suficientemente motivada y explicativa de su contenido; siendo sus alcances prácticos muy restringidos. Materialmente, el principio establecido no responde a la tradición legislativa nacional no es aceptado en la legislación comparada, contradice el uso normal del lenguaje, y no se adecua a una interpretación sistemática, lógica, progresiva y adecuada a la Constitución, dado que permite al juez crear una tercera ley que vulnera el principio de separación de poderes, viola el principio de legalidad, genera inseguridad jurídica y no se acomoda a los fines de prevención de la pena.

Palabras clave: Unidad o combinación de leyes - legalidad - seguridad jurídica - favorabilidad - interpretación integradora.

\begin{abstract}
The Supreme Court, by means of a Plenary Agreement for majority, it has consecrated the principle of combination of criminal statutes. Formally, the adopted decision doesn't have normative effectiveness because it doesn't reflect an unanimous position, him sufficiently motivated and explanatory of its content; being its very restricted practical reaches. Materially, the established principle doesn't respond to the national legislative tradition; it is not accepted in the comparative legislation; it contradicts the normal use of the language; and it is not adapted to a systematic interpretation, logic, progressive and appropriate to the Constitution, since it allows the judge to create a third law that harms the principle of separation of powers; it violates the principle of legality; it generates juridical insecurity and he doesn't make comfortable to the ends of prevention of the sanction.
\end{abstract}

Key words: Unit or combination of laws-legality-artificial security-integrative interpretation.

\footnotetext{
* Vocal Titular de la Corte Superior de Justicia de Lima. Docente universitario y profesor de la Academia de la Magistratura.

- Mi agradecimiento a Christian Cerna Manyari, por su valiosa ayuda en la elaboración de este artículo.
} 


\section{Sumario}

1. Introducción. 2. Problemas formales del Acuerdo Plenario: 2.1. Naturaleza jurídica y eficacia normativa del Acuerdo; 2.2. Problemas aplicativos; 2.3. Impacto de la decisión. 3. Interpretación y desvinculación del precedente: 3.1. Antecedentes históricos; 3.2. Diferencias gramaticales; 3.3. Legislación comparada; 3.4. Implicancias sistemáticas; 3.5. Interpretación (des)integradora; 3.6. Finalidad de la aplicación total de la norma. 4. Conclusión.

\section{INTRODUCCIÓN}

Constituye una afirmación paradigmática señalar que la norma jurídica es una estructura lógica, conformada en general por un supuesto de hecho y una consecuencia jurídica ${ }^{1}$. En el ámbito penal, esta aseveración es aún más relevante por estrictas exigencias de legalidad, y en particular por las consecuencias que este principio genera ${ }^{2}$. La ley "es la única base de la incriminación de comportamientos y de la imposición de sanciones penales" ${ }^{\prime \prime}$. Sin embargo, como las normas no son inmutables, ni las valoraciones que las sustentan estáticas, esta unidad es puesta en cuestión, cuando aquéllas se suceden en el tiempo y deben ser sometidas para su aplicación, a un juicio de favorabilidad. Surge entonces la discusión si la ley - o mejor la norma penal- debe ser interpretada como una unidad indisoluble o puede ser (re) conformada tomando los aspectos más favorables de una y otra norma que se sucede en el tiempo.

La cuestión planteada no sería más que un placentero ejercicio académico, sino fuera por que ha sido revivida y medianamente zanjada por la Corte Suprema mediante un Acuerdo Plenario. En efecto, en Sala Plena de los señores Vocales Supremos en lo Penal, de fecha 13 de octubre de $2006^{4}$, la máxima instancia de justicia acordó por 10 votos contra 4: a) "Establecer como doctrina legal, respecto al principio de combinación de leyes, que es de aplicación en el conflicto de leyes penales en el tiempo, pudiendo escogerse lo más favorable de una u otra ley, siempre que sea más favorable al reo..."; b) "Precisar que los principios jurisprudenciales antes mencionados constituyen precedentes vinculantes para los magistrados de todas las instancias judiciales...". y c) “... que en todo caso, las Ejecutorias Supremas dictadas con anterioridad, en cuanto a la doctrina legal que consignaron, quedan modificadas conforme a los términos del presente Acuerdo Plenario". 
En el presente artículo abordaremos tanto los problemas formales que dicha decisión plenaria plantea, con relación a su naturaleza jurídica, fuerza vinculante, aplicabilidad e impacto; así como los argumentos históricos, semánticos, comparados, lógicos, sistemáticos y teleológicos que abonan para una desvinculación de sus alcances.

\section{PROBLEM AS FORMALES DEL ACUERDO PLENARIO}

\subsection{NATURALEZA JURÍDICA Y EFICACIA NORMATIVA DEL ACUERDO PLENARIO}

El primer problema formal que plantea el presente Acuerdo Plenario es la determinación de su naturaleza jurídica. La cuestión no es baladí porque tiene incidencia en la fijación de los objetivos de la decisión, en el grado de obligatoriedad del acuerdo, y en la consecuencia jurídica y disciplinaria o penal de su inobservancia ${ }^{5}$.

El Acuerdo Plenario se adoptó en el marco de la facultad que tienen los integrantes de las Salas Especializadas de la Corte Suprema, para reunirse en plenos jurisdiccionales nacionales, a fin de concordar jurisprudencia de la especialidad $\left(116^{\circ}\right.$ del Texto Único Ordenado de la Ley Orgánica del Poder Judicial - L.O.P.J.). En este sentido, queda claro tanto la forma de la convocatoria, como el objetivo de la reunión plenaria. Esta facultad es a su vez complementada, conforme el Acuerdo, por su publicación fijando un principio jurisprudencial ${ }^{6}$ de obligatorio cumplimiento en todas las instancias judiciales $\left(22^{\circ}\right.$ L.O.P.J.).

Sin embargo, la aplicación de ambas normas deja en la incertidumbre si en el presente caso es igualmente aplicable el procedimiento para establecer sentencias plenarias ${ }^{7}$, previsto en el artículo $301^{\circ}$-A del Código de Procedimientos Penales. Una respuesta rápida indicaría que la decisión reúne los requisitos de dicha norma; esto es: a) El objeto de la decisión había sido materia de criterios discrepantes sobre la aceptación del principio de combinación de leyes ${ }^{\varepsilon}$; b) La decisión se expresó formalmente en una sentencia plenaria, en el entendido que fue adoptada por un Pleno Penal de la Corte Suprema y no por una Sala determinada (sentencia normativa - artículo $301^{\circ}$ A primer párrafo); y c) Fue acordada por la mayoría absoluta de los señores Vocales Supremos asistentes al Pleno.

Ahora bien, esta norma no fue invocada expresamente en la decisión plenaria; por lo que dicha omisión genera duda sobre la obligatoriedad formal del 
acuerdo; pues si se asume que la "sentencia vinculante" se sustenta en el articulo $22^{\circ}$ de la L.O.P.J. nos encontramos ante "una suerte de vinculación u obligatoriedad relativa, en cuya virtud los magistrados pueden apartarse, por excepción, a condición que motiven adecuadamente la razón de su discrepancia" ${ }^{\prime \prime}$. Por el contrario, si la decisión se encuadra en la norma procesal, la vinculación $u$ obligatoriedad es absoluta, sin posibilidad de inaplicación por los magistrados de todas las instancias ${ }^{10}$. En este caso, el carácter obligatorio del precedente proviene de la propia ley ${ }^{11}$.

Tres razones nos llevan a asumir la relativa vinculación del presente Acuerdo. Primero, en la decisión mayoritaria no se invoca expresamente el artículo $301^{\circ}$ -A del Código Procesal Penal - CPP, con lo que por razones de predictibilidad y certeza, los Magistrados asumen que queda la posibilidad de desvinculación regulada en el artículo $22^{\circ}$ L.O.P.J ${ }^{12}$. Segundo, el contenido de la propia decisión deja un espacio a la discrecionalidad cuando señala que se "puede" escoger lo más favorable de una y otra ley, siempre que sea más favorable al reo (párrafo 15) ${ }^{13}$. Tercero, aún cuando no sea una razón formal, desde la perspectiva de la fuerza normativa de la decisión, este Acuerdo reveló a diferencia de los demás Acuerdos de los Plenos Jurisdiccionales de la Corte Suprema que no hubo consenso en la decisión plenaria.

\subsection{PROBLEMAS APLICATIVOS DE LA DECISIÓN}

La decisión adoptada no delimita el ámbito de aplicación del principio de combinación. Tampoco establece criterios para la realización del juicio de favorabilidad. Por tanto, el contenido general de la decisión tiene teóricamente amplias posibilidades de aplicación. Así, cuando se dice que, en caso de conflicto de leyes penales en el tiempo, se puede escoger lo más favorable, dicha amplitud se evidencia en la vaguedad del significante "ley penal", como vehículo de expresión de normas legales ${ }^{14}$. Con dicho término se puede aludir a lo que en doctrina se denomina el "tipo de garantía" (Garantietatbestand); vale decir, a toda previsión normativa que regule "el conjunto de presupuestos materiales que condicionan la aplicación y determinación de una pena; abarca por tanto, la descripción normativa de la conducta, así como las características a la antijuricidad, culpabilidad y, en su caso, las condiciones objetivas de punibilidad, respectivamente"15.

Asimismo, puede considerarse bajo este término a todo un cuerpo normativo especial; por ejemplo, "las diferentes normas legales dictadas para definir y establecer la pena del delito de terrorismo. En este caso, se debería comparar cada uno de los decretos o leyes en su conjunto para fijar cuál es la ley más 
favorable"16. En realidad, el ámbito de comparación debe circunscribirse a lo que, en puridad, son normas penales (homogéneas); esto es, dispositivos legales compuestos cada uno por un supuesto de hecho y una consecuencia jurídica, que regulan la misma institución penal.

Por otro lado, el Acuerdo por mayoría se limita únicamente a consagrar el principio general de combinación favorable de la ley penal, pero no señala los criterios para establecer "lo más favorable" (omisión del procedimiento). No se trata, como señala Hurtado, de hacer una comparación abstracta de leyes; por ejemplo, de comparar sólo la severidad de las penas, sino todos los factores de los que depende la posibilidad, el tipo y la forma de punición ${ }^{17}$. De este modo se abre una gama de posibilidades, determinables por el particular entender del intérprete. Incertidumbre que se acentúa por el hecho que ésta es una tarea privativa del juez, a diferencia de lo que prevé la legislación española, que permite la intervención del procesado en la determinación de lo favorable ${ }^{18}$. Por tanto, el intérprete debe determinar, en función de las condiciones de cada caso concreto, lo más favorable de cada ley, pues el Acuerdo Plenario no señala los supuestos que son susceptibles de combinación.

En resumen, al depender la determinación de los aspectos favorables, de la concepción particular de quien lo aplica, se genera una situación complicada en caso de comparación de condiciones de punibilidad; circunstancias de atenuación o agravación o penas únicas o acumulativas.

\subsection{IMPACTO DE LA DECISIÓN}

No obstante lo antes señalado podemos imaginarnos los supuestos teóricos de combinación; esto es:

a) Una ley penal que establezca un tipo básico más favorable con otra ley penal cuya penalidad también lo sea.

b) Una ley penal que no establezca una circunstancia agravante, con otra que prevea una pena más favorable en la circunstancia agravada.

c) Una ley penal que prevea un tipo básico o agravado más favorable con otra ley que regule condiciones de punibilidad más favorables.

d) Una ley penal que regule una institución de la parte general más favorable, con otra ley penal que no tenga esta connotación.

Empero, la tendencia jurisprudencial solo se ha expresado en este último supuesto y vinculado a la determinación del plazo de prescripción; esto es, que la ley anterior (Código Penal-CP- 1924) sea más favorable en el cómputo 
del plazo de prescripción en función del tipo de pena, aún cuando admita la dúplica del plazo, en tanto que la ley posterior (CP 1991) haya sido más favorable al no admitirla.

Con esta limitada posibilidad de aplicación del principio sentado, es de preguntarse si el objeto de discusión por el Pleno Jurisdiccional era de tal relevancia práctica que merecía ser consagrada como "doctrina legal"; más aún si la misma no está consolidada como veremos a continuación.

\section{INTERPRETACIÓN Y DESVINCULACIÓN DEL PRECEDENTE}

\subsection{ANTECEDENTES HISTÓRICOS}

En el Código de 1924 se regulaba la aplicación de la ley más favorable al reo, cuando se producían "...modificaciones de la ley penal posteriores a la perpetración del hecho punible" (artículo $7^{\circ}$ ). Igualmente "Las modificaciones de la ley penal dictadas después de la sentencia o durante la condena" limitaban la pena conforme a la ley más favorable (artículo $8^{\circ}$ ). Sin embargo, el expositor de motivos del Código derogado no planteó expresamente la cuestión de la combinación de leyes penales. Implícitamente podía colegirse que cuando fundamenta el alcance de lo que llamaba "retroactividad benigna", asumía el principio de "unidad de la ley penal"; esto es, que "la nueva ley rige de preferencia a la antigua a favor del delincuente. Después del fallo la nueva ley limita la pena o la suspende definitivamente"19.

En la Constitución de 1933 no se hace mención alguna al principio de favorabilidad. Es recién con la Constitución de 1979, que se consagra como garantía de la administración de justicia "la aplicación de lo más favorable al reo en caso de duda o de conflicto en el tiempo de leyes penales" (artículo $233^{\circ}$ inciso 7 ).

Ahora bien, pese a la amplitud del sentido gramatical expresada en el texto constitucional de 1979, en los primeros proyectos de Código Penal se asumió una postura contraria a la combinación de leyes. Así, en el proyecto de setiembre de 1984 se señalaba que "Las modificaciones de la ley posteriores a la perpetración del hecho punible, se aplicarán en la sentencia si fueren más benignas que las disposiciones anteriores" (artículo12 ${ }^{20}$. Dicha postura se expresa claramente en los Proyectos de agosto de 1985 y marzo de $1986^{21}$, cuando se establece que "No se puede recurrir a leyes de diversa época para lograr, con su aplicación conjunta, una regla más favorable" (artículo $5^{\circ}$, segundo párrafo). Este criterio restrictivo fue descartado en los sucesivos 
proyectos de Código Penal 1989 y 1990, en los que se señaló que “La ley penal aplicable es la vigente en el momento de la comisión del hecho punible. No obstante, se aplicará lo más favorable al reo en caso de conflicto en el tiempo de leyes penales" (artículo $11^{\circ}$ ). Paradójicamente, en el Proyecto de enero de 1991, se arriba a la redacción del Código vigente, pero conservando en la Exposición de Motivos la posibilidad de aplicar de manera combinada leyes penales.

En efecto, esta contradicción se consagra con la promulgación del Código vigente, pues se señala por un lado en el artículo $6^{\circ}$ que: "La Ley penal aplicable es la vigente en el momento de la comisión del hecho punible. No obstante, se aplicará la más favorable al reo, en caso de conflicto en el tiempo de leyes penales", y se explica, por otro lado, que "En acatamiento del artículo $233^{\circ}$ inciso 7 de la Constitución Política se prescribe la aplicación de lo más favorable al reo en caso de conflicto en el tiempo de leyes penales" sustituyéndose de esta manera "el principio de la unidad de ley aplicable.... por el nuevo principio de la combinación, que toma lo más benigno que tenga cada una de las normas sucesivas"22.

La incongruencia referida se supera con la Constitución de 1993, cuando se ratifica como principio de la función jurisdiccional "la aplicación de 'la ley' más favorable al procesado en caso de duda o de conflicto entre leyes penales". (artículo 139, inciso11), y se establece que "Ninguna ley tiene fuerza ni efectos retroactivos, salvo en materia penal, cuando favorece al reo". (artículo $103^{\circ}$ ). La mención genérica a "la ley" es incluso mantenida con la modificación de este artículo, mediante Ley de Reforma Constitucional No 28389.

El seguimiento entonces de la evolución histórica de la aplicación favorable de la ley penal en el tiempo, nos permite colegir dos conclusiones preliminares: a) La aplicación combinada de leyes penales no forma parte de nuestra tradición legislativa, con la salvedad ciertamente imperativa de la Constitución del 79; b) Una interpretación adecuada, progresiva y consecuente del texto constitucional derogado, quedaría desfasada con el nuevo texto constitucional en la materia, de fecha posterior al Código vigente.

\subsection{DIFERENCIAS GRAMATICALES}

Cuando el expositor de motivos del Código vigente aludía al acatamiento de lo dispuesto por la Constitución derogada, se estaba aparentemente refiriendo a que el artículo neutro "lo" se le aplicaba en su función gramatical de acompañamiento a un adjetivo determinativo (lo uno y lo otro más 
favorable). No estaba aludiendo de manera excluyente a una ley penal, en desmedro de otra. De esta manera se extendía el ámbito de determinación a aspectos parciales e indistintos de dos objetos de comparación; en este caso de dos leyes penales en conflicto.

No obstante, el sentido gramatical del texto constitucional varía cuando dicho artículo neutro es reemplazado por el artículo determinado "la", que restringe el ámbito de aplicación a sólo un objeto de comparación (la ley más favorable), con lo que el intérprete, en estricta aplicación de la regla gramatical, deberá elegir entre dos leyes penales, aquélla que en su integridad la adjetive como más favorable.

Ciertamente, el argumento lingüístico constituye un punto de referencia importante pero insuficiente y no siempre considerado por el intérprete. En este sentido, en el Acuerdo Plenario se omite evaluar este aspecto, asumiendo tal vez que el texto del artículo $6^{\circ}$ es claro y que su sentido se autosatisface con una concepción subjetiva de la interpretación. Así, se señala en esta perspectiva que "el legislador ha consagrado el principio de combinación en la Exposición de Motivos del Código Penal..."23. Esta afirmación consagratoria es una forma de atribuirle un sentido como si fuera el expresado intencionalmente por el legislador real. La supuesta voluntad del legislador es, en ese caso, sólo una manera disimulada de atribuir un sentido a la norma, invocando -para lograr su aceptación- la autoridad del legislador"24.

\subsection{LEGISLACIÓN COMPARADA}

El reconocimiento de la ley (norma) penal como una unidad o estructura lógica, aún en casos de favorabilidad, es igualmente comprobada en la legislación comparada.

Así, la Convención Americana de Derechos Humanos y el Pacto Internacional de Derechos Civiles y Políticos disponen, con idéntico tenor, que "si con posterioridad a la comisión del delito "la ley" dispone la imposición de una pena más leve, el delincuente se beneficiará de ello" 25 . En el mismo sentido, aún cuando con menor claridad, en el Estatuto de la Corte Penal Internacional se establece que "De modificarse el derecho aplicable a una causa antes de que se dicte la sentencia definitiva, se aplicarán las disposiciones más favorables a la persona objeto de la investigación, el enjuiciamiento o la condena" (artículo. 24 inciso 2). La falta de contundencia en la exclusión del principio de combinación se explica por el uso único del término le droit en la versión francesa del Estatuto y que, en la versión española alude primero 
a la "modificación del derecho aplicable" y, luego, a "las disposiciones más favorables". Como fuera, en ambas versiones siempre aparece el artículo determinado que engloba al sustantivo (normativo) como una unidad.

En el ámbito de la legislación comparada occidental se ratifica la misma tendencia. Al respecto, el Código Penal Alemán en su numeral 2.3 establece: "Si la ley vigente durante la consumación del hecho es modificada antes del fallo, debe aplicarse la ley más benigna"26. En el artículo 112-1 del Código Penal Francés se señala que excepcionalmente "las nuevas disposiciones se aplican a las infracciones cometidas antes de su vigencia y que no hayan sido objeto de condena firme, cuando sean menos severas que las disposiciones anteriores" 27 . Por su parte, en el Código Penal Portugués se prevé que "cuando las disposiciones penales vigentes al momento de la realización del hecho punible fueran diferentes a las establecidas en leyes posteriores es siempre aplicable el régimen que concretamente es más favorable al agente..." ${ }^{\prime 2}$. En el Código Penal Italiano se señala lo siguiente: "Si la ley vigente al momento de cometido el delito y la posterior es diferente, se aplica la disposición más favorable al reo..." (artículo $2^{\circ}$ ).

En Iberoamérica el panorama legislativo no es muy diferente. Con matices de redacción que no inciden en la cuestión de fondo, se reconoce que en caso de sucesión de leyes se aplica la ley más benigna al reo. Así, se deduce el carácter unitario de la aplicación favorable con expresiones como: "la (ley) más benigna" (Argentina: artículo $2^{\circ}$; Puerto Rico: artículo 8.b); “la (nueva) ley más favorable" (Cuba: artículo 3; Panamá: artículo 13; ; Costa Rica: artículo $13^{\circ}$ ); "efecto retroactivo de las leyes penales" (España: artículo. $2^{\circ}$; Honduras: artículo $9^{\circ}$ ); "las leyes...que sean favorables" (Ecuador; artículo $2^{\circ}$ ); "La ley permisiva o favorable ... se aplicará" (Colombia: artículo $6^{\circ}$ ); "La ley posterior que de cualquier modo favorece al agente..." (Brasil: artículo $2^{\circ}$ ).

\subsection{IM PLICANCIAS SISTEMÁTICAS}

El artículo $6^{\circ}$ del Código vigente, como toda norma jurídica, se engarza dentro de un contexto; vale decir, su posible sentido interpretativo debe tener en cuenta el ordenamiento jurídico en general, y sobre todo el contexto constitucional, cuyo contenido puede variar, aunque con mayor rigidez.

En la sustentación por mayoría del Acuerdo Plenario, se invoca como argumento constitucional "el principio consagrado en el segundo párrafo del artículo $103^{\circ}$ de la Constitución Política, que establece la retroactividad de la Ley penal más favorable en caso de duda o de conflicto entre leyes penales, y que tácitamente desplaza a la regla tempus regit actum (considerando 6). 
Argumento que es reforzado con el parafraseo del artículo $139^{\circ}$ inciso 11 del texto constitucional (considerando 7).

Sin embargo, las normas invocadas como premisas legales por la decisión mayoritaria, siendo sustancialmente lo mismo, tuvieron distinta suerte. En el caso del artículo $103^{\circ}$, éste fue modificado ${ }^{29}$. En tanto que el artículo $139^{\circ}$ inciso11 sustituyó al artículo $233^{\circ}$ de la Constitución de 1979. En el primer caso, si bien la finalidad de la modificación estuvo dirigida a precisar o restringir -según como se le mire- el ámbito de aplicación del favor rei a lo estrictamente penal -material, mantuvo en su redacción el criterio de la retroactividad penal de la ley y no de una parte de ella.

Ahora bien, las modificaciones operadas tienen tres implicancias sistemáticas para una interpretación progresiva y adecuada a la Constitución del artículo $6^{\circ}$ del Código Penal: a) Se trata de modificaciones gramaticales que inciden en el sentido esencial de lo que se preveía en la Constitución de 1979, conforme ya explicamos en el acápite 3.2; b) La modificación de las dos normas constitucionales es posterior a la entrada en vigencia de la norma penal; c) La norma constitucional conforme a sus alcances debe prevalecer sobre la norma penal.

\subsection{INTERPRETACIÓN (DES)INTEGRADORA: LEX TERTIA}

A pesar de los argumentos ya señalados anteriormente, en la doctrina minoritaria, que admite el principio de combinación se ha recurrido al criterio de la interpretación integradora. Al respecto, se señala que se trata de la integración de los aspectos favorables de dos leyes, excluyendo con ello una creación por analogía del interprete de una tercera ley. En este sentido, sostiene Bustos que no hay razones de fondo para oponerse a la combinación de leyes penales, pues existen "las leyes penales incompletas y específicamente las leyes penales en blanco que exigen su integración con otras disposiciones, siempre y cuando existan bases claras de determinabilidad legal. En el caso de la lex tertia más favorable también ocurre así. No hay lesión del principio de legalidad, sino simple interpretación integrativa a favor del reo perfectamente posible ${ }^{\prime \prime 30}$.

En el mismo sentido, aunque sin desarrollar la idea, el Acuerdo Plenario por mayoría aduce que con la aceptación del principio de combinación "no se está creando una tercera ley o lex tertia, sino que se está efectivizando un proceso de integración de normas más favorables al reo, que no colisiona con los contenidos del principio de legalidad" (considerando vinculante 12). 
Empero, la fusión de dos leyes penales no puede ser equiparada a la integración de las normas incompletas o en blanco. En el caso de las normas incompletas, nos encontramos ante "...normas penales cuya estructura, gramaticalmente acabada, no contiene supuesto de hecho y consecuencias jurídicas por estar destinadas a concretar el supuesto de hecho o la consecuencia jurídica o restringir el ámbito de aplicación de otra norma" ${ }^{\prime \prime}$. En este caso, estamos ante normas penales que requieren para la comprensión de su sentido de una aclaración, restricción o remisión. Se trata por tanto de normas que requieren ser integradas en su contenido, por la propia estructura de la misma. La exigencia de integración puede deducirse de su propio contenido. En el caso de conflicto de dos normas penales en el tiempo, éstas son normas penales completas; presentan ambas el supuesto fáctico y su consecuencia jurídica. Lógicamente, no requieren ser integradas, pues para su aplicación son autosuficientes.

Por otro lado, la norma penal en blanco es una especial forma de norma penal incompleta en la que no se expresan cabalmente los elementos específicos del supuesto de hecho de la norma secundaria, sino que se remiten a otros preceptos, para que completen la determinación de aquellos elementos ${ }^{32}$. La exigencia de integración normativa es mayormente expresa. Por ejemplo, en el delito de comercialización ilegal de especies $\left(\right.$ art. $308^{\circ}$ ) es necesario remitirnos a otras normas para determinar qué especies son legalmente protegidas y caen por tanto dentro del ámbito de protección penal.

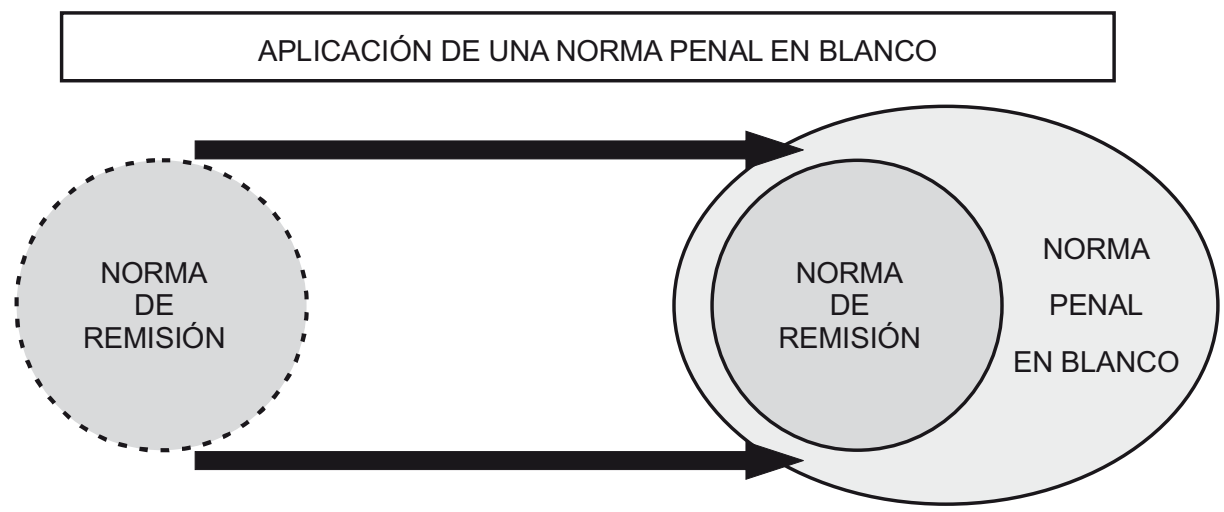

Por ende, es correcto sostener que en los dos ejemplos presentados por Bustos, se hable de una exigencia lógica de integración. Pero no puede decirse lo mismo, en el caso de una norma penal completa en conflicto temporal con otra. En este caso, en realidad, no se produce una integración en el sentido estricto del término. Por el contrario, la fusión de dos normas penales para formar una tercera termina desintegrando las normas fusionadas. 


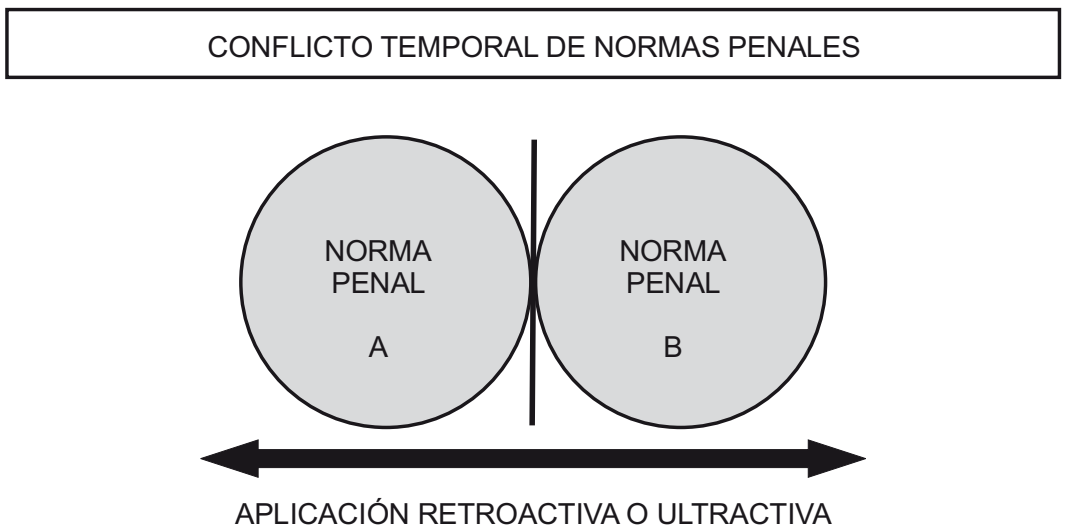

Ahora bien, para argumentar la tesis contraria a la integración no puede sostenerse que la fusión de dos aspectos parciales de normas en conflicto sea una aplicación por analogía ${ }^{33}$, pues en la integración de dos aspectos parciales de la normas no se está incorporando un elemento normativo no previsto en la ley. Se está únicamente creando desde una perspectiva lógica una tercera norma ${ }^{34}$, que resulta de fusionar aspectos parciales de dos unidades lógicas, cuyo contenido no coincide con los objetos de fusión.

\subsection{FINALIDAD DE LA APLICACIÓN TOTAL DE LA NORMA}

La necesidad de mantener integradas a las normas penales en su aplicación deriva de diversas exigencias jurídicas y de política criminal. En este sentido, la conservación de la unidad de la ley no restringe la aplicación del favor rei y mantiene incólume el principio de legalidad ${ }^{35}$. La aplicación retroactiva de la ley penal responde al imperativo de adecuar la aplicación de la norma, al cambio de valoración del legislador. Si destipifica una conducta, es evidente que los procesos e incluso las penas en ejecución queden sin efecto. $\mathrm{Si}$ introduce nuevas circunstancias atenuantes en una determinada conducta o modifica los elementos típicos de una conducta, a favor del imputado, debe igualmente adecuarse el juicio de tipicidad, a la nueva valoración. Pero en ambos casos, la reformulación del juicio de subsunción, hecha por el juzgador, está predeterminada por el legislador; responde a la modificación de un criterio de política criminal, concretado en una ley formal y que los jueces deben aplicar interpretándola. Al respecto señala Roxin que “... parece adecuado tomar como base de una sanción penal, la valoración legal existente en el momento de dictar sentencia, mientras la protección del reo u otras circunstancias especiales no hagan preciso atender al castigo previsto 
en el momento del hecho"36. En esta línea sostiene que "ello responde a una exigencia de coherencia en la aplicación del ordenamiento jurídico, ya que si los hechos han dejado de ser desvalorados por el legislador o se les desvalora en menor medida, no tiene sentido que los ciudadanos sigan padeciendo las consecuencias de unas leyes que ha dejado de considerarse adecuadas" ${ }^{\prime \prime 3}$.

\section{COMBINACIÓN DE NORMAS PENALES}

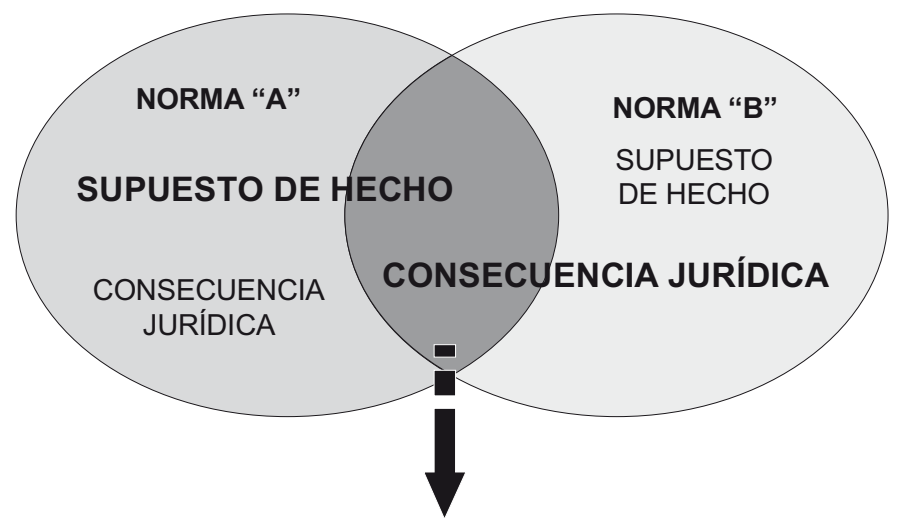

LEX TERTIA

Pero, ambos procedimientos responden al criterio político de distribución de roles dentro del Estado. El legislador legisla tipificando delitos, modificando su contenido o sus consecuencias, regulando las instituciones penales, o destipificando conductas. El juez adecua, mediante la interpretación, al caso concreto los alcances de la nueva decisión legislativa, pero en modo alguno está autorizado a tomar una parte de la valoración legislativa, para combinarla con la anterior valoración. Esta división del trabajo debe continuar así, a pesar de que la delimitación entre legislación y jurisdicción se mueva en terreno poco firme y que el protagonismo de la ley se encuentre en crisis $^{38}$. Lo fundamental, a efectos penales, es redefinir la racionalidad de la ley, dotándola de contenidos más eficaces y aplicables por los jueces.

Por otro lado, la norma penal se expresa como un mandato de aplicación general y obligatoria. Su carácter vinculante y de aplicación general tiene eficacia, en la medida que pueda ser conocida y comprendida por sus destinatarios. Por tanto, su sentido fundamental es el de motivar un comportamiento en los ciudadanos $^{39}$; cumple una función de comunicación. Como tal, la comprensión 
de su contenido sólo se puede entender de manera integral y de acuerdo a un contexto. Constituye por tanto una liberalidad sustituirse al destinatario de la norma primaria, asumiendo que esa función comunicativa se satisface con una aplicación parcial de normas; competencia de creación de leyes que no pertenece al juez ${ }^{40}$. Ello no significa que la prohibición de combinar leyes esté vinculada necesariamente a la salvaguarda de la garantía de vigencia de los derechos ciudadanos, ${ }^{41}$ pues el exceso de poder del juzgador no tiene por finalidad el desfavorecer al justiciable; en realidad lo que se cuestiona es la inobservancia de la norma secundaria como mandato al propio juez que debe aplicar la norma sin desnaturalizarla.

Esta disociación dela norma resulta aún más disfuncional a los fines preventivos de la pena, toda vez que sólo puede obtenerse un fin útil si se aplica la norma como una unidad. Por ejemplo, si se aplicase una pena accesoria de una norma penal, dejando de aplicar una pena principal de la nueva norma, por entender que es más favorable, no deja de tener una incidencia negativa en la pérdida del efecto preventivo general o especial, perseguido con la nueva sanción ${ }^{42}$. Si a ello se agrega que se aplique de manera combinada el supuesto de hecho más favorable de la anterior norma en desmedro del supuesto correspondiente de la nueva norma, no deja de desnaturalizarse el sentido de la nueva norma -entendida como una unidad-a cuyo supuesto de hecho se le asocia racionalmente una consecuencia jurídica.

No es aceptable, como se invoca en el Acuerdo, señalar que si se autoriza escoger entre dos leyes distintas -íntegramente- en el tiempo, resulte coherente y razonable que puedan combinarse, para buscar un tratamiento más favorable al reo. Esto porque la autorización se vincula a necesidades de merecimiento de pena, de justicia material o de proporcionalidad, pero que adquieren sentido, por la aplicación total de la norma más favorable. Asimismo, la mención que se hace en el Acuerdo Plenario por mayoría al principio de necesidad de la intervención penal sólo puede atenderse si "las variaciones en los preceptos que integran las normas penales y que favorecen al reo" son aplicadas globalmente. Lo único que hace el juzgador al proceder de este modo es recoger la nueva concepción jurídica del legislador, adecuando el nuevo régimen penal a favor del reo. En este caso, si es consecuente con la limitación en el ejercicio del poder punitivo realizada por el legislador.

En este sentido, el combinar aspectos favorables de dos leyes penales implica redefinir las conductas punibles o sus consecuencias; tarea en la que la ley tiene la reserva absoluta. Por ende, si como se sostiene en un Acuerdo Plenario de fecha posterior, la voluntad de los jueces no puede ser equiparada a la 
voluntad de ley ${ }^{43}$, cómo puede admitirse que se desnaturalice 'esta voluntad' superponiendo dos manifestaciones volitivas de momentos y concepciones diferentes.

\section{CONCLUSIÓN}

La finalidad perseguida por el Acuerdo Plenario en mayoría, al consagrar el principio de combinación de leyes, es ciertamente saludable. Esta decisión se inscribe dentro de la tendencia a posicionar a la jurisprudencia, dándole sentido concreto a la ley, generando con ello predictibilidad y certeza en las decisiones judiciales.

Sin embargo, esta postura se debilita si no se definen previamente los criterios formales y materiales que debe guiar la toma de decisión, para asegurar su eficacia, su legitimidad secundaria y, sobre todo, su impacto en las demás instancias de la magistratura.

Consideramos que existen sobradas razones dogmáticas y legales para exigir un replanteamiento sobre el tema abordado. Al respecto, creemos que se han presentado argumentos históricos, gramaticales, comparados, lógicos, sistemáticos y teleológicos para asumir que las normas penales se deben aplicar en su totalidad, como una sola estructura, incluso si existe la voluntad de favorecer al reo. Por lo demás, la escasa aplicabilidad del principio combinatorio no tiene la relevancia suficiente como para sacrificar otros principios que son fundamentales para un derecho penal eficaz y respetuoso de las garantías.

\footnotetext{
Villa Stein, J.. Derecho Penal. Parte General. $2^{\mathrm{a}}$ ed. Lima: San Marcos, 2001: 138.

Cfr. Roxin, C. Derecho Penal. Parte General. Tomo I. $2^{\text {a }}$ ed. Madrid: Civitas, 1997: 140 - 141

Hurtado ,J. Manual de Derecho Penal. Parte General I. $3^{\text {a }}$ ed. Lima: Grijley, 2005: 150.

Pleno Jurisdiccional de las Salas Penales Permanente y Transitorias- Acuerdo Plenario Nº 2-2006/CJ-116.

Sobre el contenido de estos aspectos cfr.: San Martín, C. La Jurisprudencia vinculante de la Corte Suprema de Justicia de la República. El ámbito Penal; en: Precedentes Vinculantes en Materia Penal. Lima: Reforma, 2008: 11-16

6 Con el término principio jurisprudencial se alude a lo que impropiamente se denomina "doctrina legal". Cfr. Paredes, J. La predictibilidad jurídica y el precedente. Lima: San Marcos, 2008: 25.

Sobre el concepto de sentencia normativa: Paredes, J. Ibid: 25.

8 Aun cuando, el Pleno Jurisdiccional tomó como referencia dos Ejecutorias (Ns. 69-2005 y 110-2005) que aceptaban el principio de combinación, la posición contraria también se expresó en Ejecutorias Supremas anteriores. Cfr. Hurtado, J. Tbid.: 302-305. También: La Determinación de la Ley Penal más favorable en el tiempo. Jurisprudencia penal comentada. En Actualidad Jurídica. Tomo 142. Setiembre, 2005: 108-112.

San Martín, C. Ibid.: 15.

San Martín, C. Ibid.: 15.

11 Castillo Alva, J. El uso de los precedentes judiciales en materia penal como técnica de argumentación racional, su alcance y valor en el derecho peruano. En Revista Electrónica Anuario de Derecho Penal. www.unifr.ch. : 37.
} 


\section{Aldo Martín Figueroa Navarro - ¿Aplicación total o combinada de normas penales? A propósito de un (des)Acuerdo Plenario}

12 La mayoría de los Acuerdo Plenarios dejan a salvo, en su parte dispositiva, la excepción de apartamiento del art. $22^{\circ}$. Cfr. Precedentes vinculantes en materia penal. Lima. Reforma: 2008.

13 Otra sería la situación si se hubiera dicho, por ejemplo: "en caso de conflicto de leyes en el tiempo, debe escogerse lo más favorable al reo, de una u otra ley".

14 Mir Puig, S. Derecho Penal. Parte General. $4^{\text {a }}$ ed. Barcelona 1996: $26-27$.

15 Quintero, G Manual de Derecho Penal. Parte General. 2a ed. Navarra: Aranzadi, 2000: 299.

16 Hurtado, J. Ibid: 304.

17 Hurtado, Jé. Ibid. 301.

18 Artículo. 2.2. Código Penal Español: “...en caso de duda sobre la determinación de la ley más favorable, será oído el reo".

19 Exposición de Motivos del Código Penal de 1924.

20 El Anteproyecto de octubre de 1984 no preveía norma alguna al respecto.

21 Publicado en el Diario Oficial "El Peruano" con fecha 19 de agosto de 1985.

22 Exposición de Motivos del Código Penal de 1991.

23 Párrafo 13 del Acuerdo Plenario. Al margen de lo inaprensible de la noción abstracta de la "voluntad del legislador", en cuerpos colegiados como el Congreso, resulta dudoso que esta voluntad se haya expresado en la exposición de motivos, que fuera preparada por los especialistas que conformaron la Comisión Revisora.

24 Hurtado, J. Ibid.: 198.

25 Artículo. 9 de la Convención Americana de Derecho Humanos - CADH y artículo 15.1 del Pacto Internacional de los Derechos Civiles y Políticos - PIDCP.

26 "§ 2 Zeitliche Geltung (...): Wird das Gesetz, das bei Beendigung der Tat gilt, vor der Entscheidung geändert, so ist das mildeste Gesetz anzuwenden".

27 "article 112-1: ...les dispositions nouvelles s'appliquent aux infractions commises avant leur vigueur et n'ayant pas donné lieu à une condamnation en force de chose jugée lorsqu'elles sont moins sévères que les dispositions anciennes ".

28 "Artigo $2^{\circ}: 4$. Quando as disposiçoes penais vigentes no momento da prática do facto punible forem diferentes das establecidas em leis posteriores, é siempre aplicado o regime que concretamente se mostrar mais favorable ao agente...".

29 La modificatoria se dio como dijimos mediante la Ley de Reforma Constitucional $\mathrm{N}^{\circ} 28389$, del 17 de diciembre de 2004, aun cuando no modifica el criterio del favor rei, para la aplicación retroactiva de la ley penal.

30 Bustos, J. Derecho Penal. Parte General. Obras completas. Tomo I. Lima: ARA, 2004: 600.

31 Villa Stein, J. Ibid.: 139.

32 Villa Stein., J. bid.: 140

33 Caro John considera por el contrario que la analogía es una forma de integración ¿Combinación de leyes penales? En Anuario de Derecho Penal 2005: 343.

34 Muñoz, F y García, M. Derecho penal, parte general, 6a. Ed. Valencia: Tirant lo Blanch, 2004, p. 146. En el mismo sentido: Zaffaroni Eugenio. Manual de Derecho Penal. Buenos Aires: EDIAR, 1987: 179, y Bacigalupo Z., Enrique, Manual de Derecho Penal, Bogota, Temis, 1996: 58

35 Urquizo, J. El principio de combinación en el nuevo Código Penal. En Revista Peruana de Ciencias Penales. Año I - Número I, 1993: 257.

36 Roxin, C. Ibid.: 166-167.

37 Muñoz, Francisco y García, Mercedes: Ibid.: 141

38 Diez, José. Presupuestos de un modelo racional de legislación penal. En Revista de Ciencias Penales Nº 15. Lima: IDEMSA, 2004155.

39 Caro, J. ¿Combinación de leyes penales? En Anuario de Derecho Penal 2005: 341.

40 Quintero, G. Manual de Derecho Penal. Parte General. 2a ed. Navarra: Aranzadi, .2000: 164.

41 Caro,J. Ibid.: 335.

42 Hassemer y Jakobs refieren por el contrario que "en caso de leyes que contemplan diversas penas, es posible y debido aplicar la nueva pena principal, si es más favorable que la de la ley anterior, y simultáneamente dejar sin aplicación la pena accesoria que acompaña a esa nueva pena principal, pues "debe partirse de que cada reacción penal tiene su propio peso y, especialmente en relación con las penas principales y accesorias, su propia definición de objetivos...". Citados por Eser, A. En: Schönke/Schröder, Strafgesetzbuch. Kommentar, 25a Ed. Beck, München, 1997: § 2 num. 34.

43 Cfr. Acuerdo Plenario No 1-2007/ESV-22, del 16.11.07. 